\title{
Práticas inovadoras para o cuidado em saúde
}

\author{
INNOVATIVE PRACTICES FOR HEALTH CARE \\ PRÁCTICAS INNOVADORAS PARA EL CUIDADO EN LASALUD
}

\section{Sônia Barros', Márcia Aparecida Ferreira de Oliveira², Ana Luisa Aranha e Silva ${ }^{3}$}

\section{RESUMO}

A necessidade de se construir um novo olhar para o cuidado baseado no diálogo e na criatividade possibilita a transformação social do papel dos profissionais no exercício da sua prática. Entende-se, neste artigo, que cuidar é mais que um ato: é uma atitude. Além disso, o arcabouço conceitual da reabilitação psicossocial é um instrumental que pode possibilitar a construção desse novo olhar. Nesta perspectiva, cuidaré considerar a importância da construção de projetos de vida, significativos para cada usuário, como eixo central da ação terapêutica. As transformações necessárias na prática em saúde mental e na enfermagem psiquiátrica estão avançando, pois os conhecimentos produzidos nesta área incorporam estratégias de acolhida e continência que consideram, em todos os momentos, o exercício da cidadania ativa dos portadores de transtornos mentais.

\section{DESCRITORES}

Acolhimento.

Saúde mental.

Enfermagem psiquiátrica.

Cuidados de enfermagem.

\begin{abstract}
The need to build a new look to the care, based on dialogue and creativity, enables the social transformation of the role of professionals in their practice. It is understood here that the care is more than an act: it is an attitude. Moreover, the conceptual framework of psychosocial rehabilitation is an instrument that might enable the construction of this new look. In this context, to care is to consider the importance of building projects of life, significant for each user, as lynchpin of the therapeutic action. The necessary changes in mental health's practice and psychiatric nursing are progressing, since the knowledge produced in this area incorporates strategies to welcome and maintenance which considers, at all times, the exercise of active citizenship of the mental patients.
\end{abstract}

\section{KEY WORDS}

User embracement.

Mental health.

Psychiatric nursing.

Nursing care.

\section{RESUMEN}

La necesidad de construir una nueva perspectiva para el cuidado, basado en el diálogo y en la creatividad, torna posible la transformación social del rol de los profesionales en el ejercicio de su práctica. En el presente artículo, se entiende el cuidar como más que un acto: una actitud. Además, el marco conceptual de la rehabilitación psicosocial se muestra como un instrumento que posibilita la construcción de esa nueva perspectiva. En ese aspecto, cuidar es considerar la importancia de construir proyectos de vida, significativos para cada usuario, como principal foco de la acción terapéutica. Los cambios necesarios en la práctica de salud mental y enfermería psiquiátrica están avanzando, ya que el conocimiento producido en esta área incorpora estrategias para acoger $\mathrm{y}$ adherir que considera, en todo momento, el ejercicio de la ciudadanía activa de los enfermos mentales.

\section{DESCRIPTORES}

Acogimiento.

Salud mental.

Enfermería psiquiátrica.

Atención de enfermería.
1 Enfermeira. Professor Associado do Departamento de Enfermagem Materno-Infantil e Psiquiátrica da Escola de Enfermagem da Universidade de São Paulo. sobarros@usp.br

2 Enfermeira. Professor Doutor do Departamento de Enfermagem Materno-Infantil e Psiquiátrica da Escola de Enfermagem da Universidade de São Paulo. marciaap@usp.br

3 Enfermeiro. Professor Doutor do Departamento de Enfermagem Materno-Infantil e Psiquiátrica da Escola de Enfermagem da Universidade de São Paulo. anaranha@usp.br 


\section{INTRODUÇÃO}

O relato que se segue é fruto das reflexões que temos feito na área de enfermagem psiquiátrica e de saúde mental da Escola de Enfermagem da Universidade de São Paulo que, historicamente, carregava o fardo de assistir pelo controle e pela disciplina. Nas últimas décadas, a área vem se debruçando sobre a sua própria constituição e redefinindo o seu processo de trabalho de cuidar e ensinar.

A implementação efetiva da reforma psiquiátrica, ou seja, as ações dessa política traduzem-se em práticas específicas que recolocam a discussão sobre o significado do cuidado em saúde mental ${ }^{(1)}$.

O novo modelo assistencial reconfigurou o objeto de intervenção - não mais a doença e sim o sujeito-social com transtorno mental - e, conseqüientemente, a sua finalidade não mais a remissão do sintoma, mas as necessidades de saúde propriamente humanas - e os instrumentos de intervenção, ou seja, os saberes e as práticas.

As mudanças ocorridas no interior do campo da saúde mental, particularmente os referentes ao objeto e à finalidade do processo de trabalho, situam-se no âmbito da vida emocional e da emancipação do sujeito-usuário, para a ampliação da sua autonomia e da sua reabilitação psicossocial ${ }^{(2)}$.

Este panorama tem sido um desafio constante para os profissionais da área, tanto do ensino quanto da assistência, pois implica na transformação do saber e do fazer das profissões, para se organizar novas bases teóricas e práticas para a condução de projetos assistenciais e, assim, inventar novas maneiras de produzir saúde.

Essa invenção de novas formas de produzir saúde passa obrigatoriamente pela modificação do processo de trabalho das equipes, implicando na apropriação coletiva do desafio da construção de novas formas de responsabilização, e na assunção do problema de saúde/necessidades representada pelo usuário como objeto da ação de saúde ${ }^{(3)}$.

Assim, são necessários técnicos que transformem suas práticas teóricas e políticas; questionem suas funções; e sejam capazes de inventar novas possibilidades de compreensão e de relacionamento com os seus objetos e objetivos do seu trabalho ${ }^{(4)}$.

No cotidiano dos serviços de atenção à saúde mental é possível presenciarmos ações dos trabalhadores que experienciam novas tecnologias pautadas na noção do cuidado ao sujeito de necessidades, de desejos e de crenças. No entanto, muito ainda há o que fazer para modificar ou criar em termos de atenção em saúde mental.
Desta maneira, é importante construir um novo olhar para o cuidado baseado no diálogo e na criatividade que possibilite a transformação social do papel dos profissionais no exercício da sua prática. É sobre esse novo olhar para o cuidar que queremos nos deter.

O modelo clínico presente no pensar e no fazer dos profissionais modernos ainda assume um espaço de poder, com relevante aceitação e consideração nos sistemas de cuidar da saúde. Mas o cuidar dele decorrente confere um caráter simplificador, mantendo-se os princípios de redução e separação entre saberes, agentes e elementos da natureza ${ }^{(5)}$.

As autoras ${ }^{(5)}$ afirmam que as dimensões históricas do cuidar, deixadas à parte pelo modelo clínico, revelam a multiplicidade e a multidimensionalidade do cuidar, que ficou à margem com o nascimento da clínica e sua ascensão na modernidade.

A história dos cuidados desenha-se em volta dos dois eixos evidenciados entre os conhecimentos, gerando duas orientações dos cuidados, das quais uma vai garantir e assegurar a manutenção e a continuidade da vida e, a outra, vai fazer recuar a morte ${ }^{(6)}$.

$\mathrm{Na}$ origem, estas duas orientações coexistem, são complementares e geram-se mutuamente. Para garantir a vida, utilizam-se conhecimentos tendo em conta tudo que é indispensável para garantir as funções vitais.

Com o nascimento da clínica, torna-se possível operar uma separação entre as duas orientações, no âmbito dos cuidados. Os cuidados de manutenção da vida passam a ser negados e excluídos do discurso biomédico moderno e os cuidados para evitar a morte, cuidados curativos, nascidos de descobertas empíricas, são reconhecidos como os únicos científicos, surgindo uma distinção entre cuidar e $\operatorname{tratar}^{(6)}$.

O cuidado clínico, um cuidado de pequena escala, assenta-se no fato fundador que a saúde é obtida com base no modelo clínico biomédico que separa o cuidador daquele que é cuidado: o tratar da doença é o super-facto ${ }^{(6)}$.

A instituição de um corpo de conhecimentos científicos produzidos no desenvolvimento da ciência médica inaugurou o campo do tratamento. Não é por acaso que a tecnologia de cuidados inaugurada por Pinel é chamada de tratamento moral. Isso quer dizer que a partir daí produzem-se formas de tratar baseados numa dada concepção de adoecimento ${ }^{(6)}$.

Neste sentido, pode-se dizer que no campo médico-psiquiátrico fala-se de tratamento e não de cuidado. Tratar seria, então, a ação mediada por conhecimentos científicos, instrumentais e objetivos. Tratar é a objetivação de um corpo de conhecimentos, traduzida numa ação profissional. 
O paradigma racionalista e a ideologia médica (mas não somente ela), que reconhece de forma absolutilizada a saúde como único valor positivo, assume para si a experiência da doença, neutralizando-a e negando-a, a fim de reduzi-la a puro objeto de sua competência. Paradoxalmente, destrói o paciente no momento em que tenta protegê-lo, afastando-o do seu encontro com a própria doença (com o próprio corpo, com a própria história, com o modo subjetivo de viver um e outra) que deve ser vista com passividade e dependência ${ }^{(7)}$.

A polarização da saúde (em positivo) e da doença (em negativo) impede qualquer sinal de relação entre um e outro, negando a relação dialética onde a saúde possa surgir como um momento de consciência da apropriação do corpo, como superação da doença enquanto experiência; e a doença uma fase da vida, uma ocasião de apropriação de si, do próprio corpo, das próprias experiências e finalmente, da saúde (se não sobrevier a morte). A conseqüência deste processo é que a própria experiência de adoecer, é vivida como um acidente que pode ser objetivável pela ciência e não como uma experiência pessoal ${ }^{(7)}$.

Aceitar esta visão de mundo seria negar a doença como o objeto exclusivo de intervenção e colocar neste lugar a vida da pessoa. Eliminada a doença como o foco da intervenção, as possibilidades de ação devem, necessariamente, ser ampliadas. Além do tratamento, a pessoa passa a ser objeto de cuidado: um ser que porta necessidades e não apenas sintomas.

Cuidar é mais que um ato: é uma atitude. Portanto, abrange mais que um momento de atenção, de zelo e de desvelo. Representa uma atitude de ocupação, preocupação, de responsabilização e de desenvolvimento afetivo com o outro ${ }^{(8)}$.

Cuidar é uma atitude de responsabilização. Responsabilizar-se é ser capaz de responder, é trazer para si a função da resposta por determinada situação ou ato. É, portanto, assumir um ato como seu ${ }^{(9)}$. A tomada de responsabilidade é um conceito derivado da psiquiatria democrática italiana que se tornou pregnante na reforma psiquiátrica brasileira. Ela pode ser pensada como uma atitude de implicação, do tipo tudo o que diz respeito a este sujeito me importa, me diz respeito diretamente. $\mathrm{O}$ ponto central é o fortalecimento dos laços entre o sujeito que busca o atendimento, o serviço e o território onde deve ser baseado o atendimento.

Logo, admitir uma ação junto ao psicótico significa adotar uma perspectiva ampla para além daquilo que convencionalmente é definido como leque de ação de um profissional de saúde mental. Esta implicação quer anular o pacto do anonimato, da suposta invisibilidade de quem se coloca nas engrenagens impessoais do serviço público. Dilui-se o discurso das especificidades, do tipo isto não me cabe, só pode ser visto pelo médico; ou: isto eu não faço, isto é trabalho para assistente social; ou: isto não diz respeito ao meu lugar de analista $^{(9)}$.
A tomada de responsabilidade significa um direcionamento da atenção, levando em conta: a escuta; o acolhimento; a ética; a autonomia; o resgate da cidadania; a subjetivação, o respeito, a liberdade e a inclusão social, dentre outros. É ao redor deste ideário e acordos comuns que profissionais com diferentes formações, com diferentes crenças e filiações teóricas, se reúnem e formam equipes multidisciplinares, que trabalham no cotidiano dos serviços de saúde mental e no campo da atenção psicossocial.

\section{O SIGNIFICADO DA INOVAÇÃO EM SAÚDE MENTAL}

A atenção psicossocial no contexto da reforma psiquiátrica brasileira vem construindo elementos teóricos e técnicos, ideológicos e éticos, constituindo-se um novo paradigma para as práticas em saúde mental capaz de substituir o paradigma psiquiátrico, ainda dominante na formação, e conseqüientemente nas práticas ${ }^{(10)}$.

Nesta compreensão, o arcabouço conceitual da reabilitação psicossocial é um instrumental que pode possibilitar a construção desse novo olhar para o cuidado.

A noção da reabilitação psicossocial permite o entendimento que qualquer processo terapêutico tem que ser parte de um projeto de intervenção planejado por toda equipe, cujos objetivos gerais dirijam-se ao incremento da: consciência do paciente a respeito dos seus problemas; autonomia afetiva-material-social do paciente; incorporação do paciente na vida de relação social e política ${ }^{(11)}$.

Trabalhar com o conceito de reabilitação psicossocial é possibilitar a desconstrução de práticas fundamentadas na objetividade da doença mental e a (re)construção de práticas voltadas para as reais necessidades do paciente; é estabelecer relações que permitam ao usuário a apropriação, a significação e a reconstrução de suas histórias de vida.

Reabilitar pode ser entendido como um processo de restituição do poder contratual do usuário, com vistas a ampliar a sua autonomia. Entende-se por autonomia a capacidade de um indivíduo gerar normas, ordens para a sua vida, conforme as diversas situações que enfrenta ${ }^{(12)}$.

A contratualidade do usuário vai estar determinada pela relação estabelecida pelos profissionais que o atendem, ou seja, se esses profissionais usarem do seu poder para aumentar o poder do usuário ou não, denominado na prática como emprestar poder contratual. Durante o processo de formação profissional há que aprender que algumas vezes é necessário utilizar o prestígio, a delegação social, o saber reconhecido pela sociedade aos profissionais, para possibilitar relações e experiências renovadas aos usuários.

O conceito de autonomia, questão central no campo assistencial em saúde mental, deve embasar o conjunto de 
práticas dos profissionais dentro de um projeto terapêutico compartilhado, entendendo que a autonomia deve ampliar as possibilidades de estabelecer novas normas e novos ordenamentos para a vida ${ }^{(12)}$.

É fundamental compreender que a cidadania é a pré-condição de qualquer processo de cuidar. A cidadania é um direito em si: soma dos direitos negativos (não ser excluído, não ser abandonado e não ser violentado) e dos direitos positivos (ser atendido nos serviços de saúde, ser bem atendido e ser reconhecido em suas necessidades) ${ }^{(13)}$.

É nesse enfrentamento do cotidiano mediado pelo uso do tempo, espaço, objetos e inter-relações, que se deve processar o cuidar, ajudando e encorajando o sujeito que precisa readquirir ou adquirir a habilidade para efetuar suas trocas e suas escolhas.

Na perspectiva da reabilitação, cuidar é considerar a importância da construção de projetos de vida, significativos para cada usuário, como eixo central da ação terapêutica.

O concreto do cotidiano das práticas será considerado uma ação de reabilitação: o desfrute de bens e serviços normalmente não desfrutados; a aquisição de uma habilidade antes não possuída; a apreciação de qualquer atividade útil desenvolvida pelo indivíduo; a elevação do meio de vida; ter, possuir propriedade privada; fazer possível o sentido de pertencimento; a ajuda oferecida para fazer com que a pessoa sinta-se como respeitável na sua diferença; o acesso às redes sociais. Não será reabilitativo preencher o tempo, por exemplo, fazendo objetos inúteis, ou seja, entretenimento ${ }^{(13)}$.

Dessa forma, é fundamental que os profissionais da saúde, particularmente os enfermeiros, considerem que a atitude em relação ao paciente fundamenta o projeto terapêutico, não importando a técnica que instrumentaliza uma intervenção. É necessário ter: a) atitude solidária afetiva que se traduz em respeito para com a experiência diferente do paciente; devolução da dignidade ao paciente; consciência da falta de poder do paciente; ruptura da hierarquização entre o poder da organização institucional e as necessidades do paciente. b) atitude psicoterapêutica, que compreenda o paciente; aceitar o que o paciente diz e vive; envolvimento emocional com limites e escutar o paciente. c) atitude reabilitatória para que o paciente possa restabelecer suas relações afetivas e sociais; reconquistar seus direitos na comunidade e reconquistar seu poder social ${ }^{(13-14)}$.

Na prática cotidiana, além de redimensionar a sua relação com as demais práticas na área de saúde e com a clientela, os profissionais ampliam seu universo de conhecimento específico.

É importante que reabilitação psicossocial não se torne um novo jargão a batizar velhas práticas, rotulando pavilhões e iniciativas particulares num todo manicomial ${ }^{(15)}$.
Aquilo que um dia chamamos de cultura manicomial hoje se apresenta vestida com outras roupagens e entre elas destaca-se um esvaziamento da dimensão subjetiva, existencial e do sofrimento mental, em prol de uma versão fisicalista, eliminativista, reducionista.

Não é preciso muito esforço para compreender porque este é um fenômeno que devemos levar a sério: ele tende a nos transformar a todos numa espécie de técnicos do bem estar, ortopedistas do espírito.

A outra face atual da cultura manicomial é uma conseqüência da crescente intolerância ao sofrimento em todas as suas formas, na nossa cultura ${ }^{(16)}$.

A dor psíquica e o sofrimento mental são cada vez menos despidos de uma significação que vai além de um estorvo a ser simplesmente eliminado da forma mais rápida e silenciosa possível. Parece haver cada vez menos sentido em perguntar o que está acontecendo comigo e por quê?, já que na verdade se acontece algo não é bem comigo, mas com regiões do meu cérebro, minhas sinapses e meus sistemas de regulação neuro-endocrinológicos ${ }^{(16)}$.

Devem ser usados todos os recursos terapêuticos que estiverem ao alcance para diminuir a dor e o sofrimento daqueles que estão sob nossos cuidados. O problema não está aí. Está no fato de que qualquer cuidado visa não apenas evitar o sofrimento desnecessário, mas também criar espaços de tolerância e modos de acolhimento e convivência com aquilo que, na vida subjetiva, é da ordem do intratável, do inevitavelmente doloroso, do que não tem remédio nem nunca terá ${ }^{(16)}$.

A loucura, a dor subjetiva, a morte e o envelhecimento não são ruídos, desvios, disfunções de uma vida que se extraviou de seu rumo. São, ao contrário, os signos de uma vida normativa. Ter saúde não é não adoecer: é poder adoecer e se recuperar; poder sofrer e ultrapassar o sofrimento engendrando novas formas de lidar com vida ${ }^{(17)}$.

Portanto, uma vida que não se depara com o intolerável, com o assombro, com o sem-sentido é uma vida empobrecida, normatizada, incapaz de agir criativamente.

\section{CONSIDERAÇÕES FINAIS}

Diante dessas questões, pode-se dizer que as transformações necessárias na prática em saúde mental estão avançando, na medida em que os conhecimentos produzidos nesta área incorporam estratégias de acolhida e continência que consideram, em todos os momentos, o exercício da cidadania ativa dos portadores de transtornos mentais. Desta forma, os profissionais da saúde tentam sair de um modelo prescritivo de instrumentalização e de técnicas para operar um modelo ético comprometido com as necessidades do sujeito social doente. 
Assim, na nossa experiência de ensino na Escola de Enfermagem da Universidade de São Paulo é possível identificar que os alunos passam a compreender o doente como sujeito de direitos e produtor de sentidos, o tratamento em uma concepção ampliada que inclui possibilidades terapêuticas diversas em que as palavras autonomia e cidadania têm significado.

\section{REFERÊNCIAS}

1. Barros S, Egry EY. O louco, a loucura e a alienação institucional: o ensino de enfermagem psiquiátrica sub judice. Taubaté: Cabral; 2000 .

2. Barros S, Silva ALA, Oliveira MAF. Inclusão social de pessoas com transtornos mentais severos e persistentes. Cad IPUB. 2000;(15):215-22.

3. Merhy EE. Em busca do tempo perdido: a micropolítica do trabalho vivo em saúde. In: Merhy EE, Onocko R, organizadores. Agir em saúde: um desafio para o público. São Paulo: Hucitec; 1997.

4. Amarante PDC. A (clínica) e a reforma psiquiátrica. In: Amarante PDC, organizador. Archivos de saúde mental e atenção psicossocial. Rio de Janeiro: Nau; 2003.

5. Silva ALA, Fonseca RMGS. Processo de trabalho em saúde mental e o campo psicossocial. Rev Lat Am Enferm. 2005; 13(5):441-49.

6. Foucault M. Nascimento da clínica. Rio de Janeiro: Forense Universitária; 1994.

7. Basaglia F. Scritti II (1968-1980): dall'apertura del manicomio alla nuova legge sull'assistenza psichiatrica. Torino: Giulio Eunaudi; 1982. Riabilitazione e controllo sociale.

8. Boff L. Saber cuidar: ética do humano, compaixão pela terra. Petrópolis: Vozes; 1999.

9. Elia L. Responsabilidade do sujeito e responsabilidade do cuidado no campo da saúde mental [texto na Internet]. Rio de janeiro: Secretaria Municipal de Saúde; 2004. [citado 2004 out. 12]. Disponível em: http://www.saude.rio.rj.gov.br/saude/pubsms/ media/responsabilidade_do_sujeito.pdf
Nesse modo de andar o ensino parece que estamos contribuindo para a transformação da assistência psiquiátrica e das práticas de enfermagem, intervindo na formação de sujeitos em transformação em um campo de prática em transformação.

10. Costa-Rosa A. Atenção psicossocial: rumo a um novo paradigma na saúde mental coletiva. In: Amarante PDC, organizador. Archivos de saúde mental e atenção psicossocial. Rio de Janeiro: Nau; 2003

11. Saraceno B, Asioli F, Gianni T. Manual de saúde mental. São Paulo: Hucitec; 1994.

12. Kinoshita RT. Contratualidade e reabilitação psicossocial. In: Pitta AMF, organizadora. Reabilitação psicossocial. São Paulo: Hucitec; 1996.

13. Saraceno B. Libertando identidades: da reabilitação psicossocial à cidadania possível. Belo Horizonte: Te Corá; 1999.

14. Rotelli F. Per la normalità-taccuino di uno psichiatra negli anni della grande riforma scritti 1967-1998. Trieste: Scienza Nuova; 1999. Re-habilitar. La Re-habilitación Retirado do site www.exclusio.net em 20/06/2004.

15. Pitta AMF. O que é a reabilitação psicossocial no Brasil, hoje. In: Pitta AMF, organizadora. Reabilitação psicossocial no Brasil. São Paulo: Hucitec; 1996.

16. Bezerra Junior B. O cuidado nos CAPS: os novos desafios [texto na Internet]. Rio de Janeiro: Secretaria Municipal de Saúde; 2004. [citado 2004 out. 12]. Disponível em: http:// www.saude.rio.rj.gov.br/saude/pubsms/media/cuidado_nos_caps.pdf

17. Canguilhem G. O normal e o patológico.Rio de Janeiro: Forense Universitária; 1982. 